\title{
ONLINE SCHOOL FOR CHILDREN AND ITS IMPACT ON MENTAL HEALTH OF STUDENTS, PARENTS AND TEACHERS IN THIS PANDEMIC SITUATION
}

\author{
Sadya Tarannum ${ }^{1 *}$, Bushra Nayeem ${ }^{2}$, Atiqul Haq Mazumder ${ }^{3}$ \\ ${ }^{1}$ Assistant Professor, Department of Psychiatry, Khwaja Yunus Ali Medical \\ College and Hospital, Bangladesh, sadyatarannum@gmail.com \\ ${ }^{2} \mathrm{PhD}$ Candidate, History, Theory and Urbanism, University of Kansas, USA, \\ bnayeem@ku.edu \\ ${ }^{3}$ Doctoral Researcher, Faculty of Biochemistry and Molecular Medicine, \\ University of Oulu, Finland, atiq10@gmail.com \\ ${ }^{*}$ Corresponding Author
}

\begin{abstract}
Nowadays we are taking care of uncertainty and stress due to Current situation of the pandemic. Our confusion, queries and uncleanness about COVID 19 sometimes makes us unstable, insecure, dubiousness, etc. Bangladesh Government has taken necessary steps to control this situation and close all the schools till further notice. This article is embracing current educational systems in Bangladesh, its effect on mental health, challenges and overcoming solutions. Government and Private schools have already started their online classes. Online schools definitely help students to continue their education at home, keep students busy in these pandemic circumstances, helps them to share their feelings with students and teachers. An emotional bonding has been created between teachers and students and this new learning has simply given education a new lease of life. On the other hand teachers, with new ideas, make the classroom much more enjoyable for the students. However it lessens a gap in learning process but still faces lots of challenges. Most often it is difficult for teachers to touch every student in the class, in rural areas sometimes it is hard to get internet connection, children under 7 years old does not want to seat in front of a computer for more than one hour, children under 10 years need help from parents to operate computer or mobile, working parents feel problem to adjust online class schedule with their own, zoom, google class room is new for many students and parents which create trouble to attend class at proper time, and a portion of students and parents do not have smart mobile phone and computer. Few teachers are trained about this online teaching, Lack of training of teachers and less innovative ideas often make lessons less effective. It is painful for parents to pay fees regularly who lose their job due to COVID 19. On the other side of the coin is that a number of teachers are not getting full salary which often makes teaching less useful. Prolonged lockdown and significant changes to our daily lives may cause Depression, Generalized Anxiety Disorder, Panic Disorder, Obsessive Compulsive
\end{abstract}


Disorder, etc. Students, teachers, and parents any one can suffer from Mental Disorder. They are also prone to develop behavioral problems such as irritability, restlessness, palpitation, sleeping and eating problem, sudden violent and aggressive behavior, fear of dying, pain on multiple sites of the body, etc. Occasionally student's complaint of somatic problem such as headache, body ache, breathlessness, tiredness, etc. It happens due to extended lockdown, detachment from friends and non-availability of the market and playground. We always give attention to physical problem but mental health issues are also important for a productive functional life. Teachers should put some innovative ideas to make the online teaching more interesting such as regular meeting with parents, adding some audiovisual aid such as films, poster, video, allow students to play some useful games during class and take regular feedback from the students. Parents also can play an important role during this critical situation. They can also help their children to adjust with this situation. If students make themselves busy with some household works, maintain connection with friends by mobile phone and social media they can easily tackle this situation. We need to encourage and give attention to each other to overcome this situation. A great team work is highly encouraged to overcome our all challenges including technological issue. By this way we will be able to establish not only a comfort environment for both teachers and students but also can develop some active learners.

Keywords: Pandemic, Mental Disorder, Depression, Panic Disorder, Obsessive Compulsive Disorder, Behavioral Problem

\section{FULL TEXT PDF}

DOI: https://doi.org/10.47696/adved.202084

CITATION: Abstracts \& Proceedings of ADVED 2020- 6th International Conference on Advances in Education, 5-6 October 2020

ISBN: 978-605-06286-0-9 